\title{
Role of neo-adjuvant chemotherapy followed by surgery in cervical cancer: a review
}

\section{Ganesh Bharaswadkar*}

Department of Obstetrics and Gynecology, BDF Hospital, Bahrain

Received: 24 June 2020

Accepted: 31 July 2020

\section{*Correspondence:}

Dr. Ganesh Bharaswadkar,

E-mail: ganeshbbbb@gmail.com

Copyright: (C) the author(s), publisher and licensee Medip Academy. This is an open-access article distributed under the terms of the Creative Commons Attribution Non-Commercial License, which permits unrestricted non-commercial use, distribution, and reproduction in any medium, provided the original work is properly cited.

\begin{abstract}
Incidence of cervical cancer is predominantly found in developing countries. In Indian set up, it is most commonly found in rural locations in younger population. Chemotherapy was initially introduced for the treatment of recurrent/metastatic cervix cancer and has subsequently been explored in primary treatment either as neo-adjuvant prior to radiation or surgery in an attempt to reduce the incidence of loco-regional recurrence. The review study tries to evaluate the role of neoadjuvant chemotherapy (NACT) followed by surgery in cervical cancer management. Randomized trials and meta-analysis were analysed. Most of them used short course chemotherapy course of 4-6 weeks followed by surgery. patients with high risk pathological features received postoperative RT. The results of trials indicated significant reduction in the risk of death with NACT, but there were few differences between the trials. NACT followed by surgery is found to be associated with an improved response rate and progression-free survival. However, the impact on overall survival remains to be confirmed.
\end{abstract}

Keywords: Cervical cancer, Neo-adjuvant chemotherapy, Surgery

\section{INTRODUCTION}

Cervical cancer is a common malignancy among women in countries with limited resources. In India, its incidence varies from 13-24/100,000 women per year. While cervical cancer continues to be a common malignancy in rural India, it is preceded by breast cancer in urban India. ${ }^{1}$ Clinical presentation for cervical cancer in India has features distinct from those seen in industrialized nations: young age at diagnosis (median age 35-38 versus 50-58 years), higher frequency of squamous histology (>90 versus $\leq 80 \%$ ) and presence of locally advanced stage (stage IIB-IVA) in $>80 \%$ of women with a higher disease volume compared to $\leq 50 \%$. $^{2}$ The outcome for early-stage cervical cancer is generally good: the 5-year survival rates for locally advanced disease vary from 50 to $65 \%$ for stage IIB, from 28 to $35 \%$ for stage IIIB and from 5 to $15 \%$ for stage IVA disease. Thus, $30-50 \%$ of patients develop treatment failure; loco regional recurrence is the main cause of failure. The presence of a big primary tumor (bigger tumors tend to have hypoxic foci which are relatively radio-resistant) and/or pelvic/para-aortic lymph nodes har boring metastatic disease are possible contributing factors. Chemotherapy was initially introduced for the treatment of recurrent/metastatic cervix cancer and has subsequently been explored in primary treatment either as neo-adjuvant prior to radiation or surgery or as adjuvant after radiation or surgery. Currently, chemotherapy administered concurrently with radiation therapy (concurrent chemo radiation, CCRT) is the standard treatment for locally advanced cervical cancer. Authors have made an attempt to review the role of neo-adjuvant chemotherapy followed by surgery in the management of cervical cancer.

\section{DISCUSSION}

In stage II B-IV A, residual disease in almost one third of patients after sequential NACT and RT led investigators to hypothesize that the surgical extirpation of the 
remaining tumor mass may be associated with survival benefit. Many phase III studies using NACT followed by surgery with or without adjuvant RT revealed encouraging results. ${ }^{3,4}$ Later this issue was addressed in a number of randomized trials (Table 1) and metaanalysis. $^{5-12}$

Table 1: Randomized studies of NACT and surgery in patients with cervical carcinoma.

\begin{tabular}{|c|c|c|c|c|c|c|}
\hline Authors & Stage & Patients, $\mathbf{n}$ & Regimen & Survival & & P value \\
\hline & & & & $\mathrm{NACT}+\mathrm{Sx}(\%)$ & Sx/RT (\%) & \\
\hline \multirow{2}{*}{ Chang et $\mathbf{a l}^{5}$} & IBT-IIA & 124 & VBP & 2 -year OS=81 & 84 & N.S. \\
\hline & & & & 5 -year OS=70 & 61 & N.S. \\
\hline \multirow{2}{*}{$\begin{array}{l}\text { Benedetti Panici } \\
\text { et } \mathbf{a l}^{\mathbf{6}}\end{array}$} & IB2-III & 441 & Variable & 5 -year OS=58.9 & RT: 44.5 at 5 years & $<0.07$ \\
\hline & & & & $\mathrm{PFS}=55.4$ & 41.3 & $<0.02$ \\
\hline \multirow{6}{*}{$\begin{array}{l}\text { Napolitano et } \\
\mathrm{al}^{7}\end{array}$} & IB-IIA & NACT-Sx $=106$ & VBP & 5-year OS: & & \\
\hline & & $\mathrm{Sx} / \mathrm{RT}=86$ & & IB-IIA=78.6 & 73.2 & N.S. \\
\hline & & & & $\mathrm{IIB}=68.7$ & 64.3 & N.S. \\
\hline & & & & 5-year DFS: & & \\
\hline & & & & IB-IIA=71.1 & 64.3 & $<0.05$ \\
\hline & & & & $\mathrm{IIB}=56.2$ & 57.1 & N.S. \\
\hline \multirow{4}{*}{ Eddy ${ }^{8}$} & IB bulky & 288 & VP & IB-IIA: & IB: & \\
\hline & & & & $\begin{array}{l}5 \text {-year OS=78 } \\
\text { versus } 73 \%\end{array}$ & 68 versus 64 & N.S. \\
\hline & & & & $\begin{array}{l}5 \text {-year DFS=77 } \\
\text { versus } 64\end{array}$ & 56 versus 57 & \\
\hline & & & & $p<0.05$ & $\mathrm{p}=\mathrm{N} . \mathrm{S}$. & \\
\hline \multirow{2}{*}{ Cai et al ${ }^{9}$} & IB & $\begin{array}{l}\text { CT-Sx }=52 \text { versus } \\
\text { Sx alone }=54\end{array}$ & & 5 -year OS=84.6 & & $<0.01$ \\
\hline & & & & $\begin{array}{l}\text { (CT arm) versus } \\
75.9\end{array}$ & & \\
\hline \multirow{3}{*}{$\begin{array}{l}\text { Katsumata et } \\
\text { al }^{10}\end{array}$} & $\begin{array}{l}\text { IB2, } \\
\text { IIA2, IIB }\end{array}$ & $\begin{array}{l}\text { NACT-Sx versus } \\
\text { Sx alone }\end{array}$ & BOMP & 5-year OS NACT & & \\
\hline & & & & Arm $=70$ & & \\
\hline & & & & Sx arm $=74.4$ & & 0.85 \\
\hline
\end{tabular}

Adapted from ${ }^{15}$, Sx: surgery, VBP: vincristine, bleomycin and cisplatin, VP: vincristine and cisplatin, BOMP: bleomycin, vincristine, mitomycin-C and cisplatin, OS: overall survival, PFS: progression free survival, DFS: disease free survival.

Chang et al randomized 124 patients of stage I B-II A to receive either 3 cycles of cisplatin, vincristine or bleomycin followed by either hysterectomy $(n=68)$ or primary pelvic RT $(\mathrm{n}=52) .{ }^{5}$ The cumulative survival was $81 \%$ versus $84 \%$ at 2 years and $70 \%$ versus $61 \%$ at 5 years in the NACT and RT arms, respectively. There was not remarkable difference in disease free survival between the 2 arms. ${ }^{5}$ In a similar study by BenedittiPanici et al survival advantage with this strategy was limited to stage IB2-IIb. ${ }^{6}$ Most of these studies used short course chemotherapy of 4-6 weeks followed by surgery or radiotherapy. ${ }^{3-9,14}$ Katsumata et al for the Japan clinical oncology group, have reported results of a phase III trial. ${ }^{10}$ Patients with stage IB2, II A2 and II B received 24 cycles of the BOMP regimen (bleomycin, vincristine, mitomycin $\mathrm{C}$ and cisplatin every 3 weeks) followed by radical surgery versus radical surgery alone. Patients with high risk pathological features received postoperative RT. The 5-year overall survival rate was $70 \%$ in the NACT group compared to $74.4 \%$ in the radical surgery group
$(\mathrm{P}+0.85) .58 \%$ of patients received postoperative $\mathrm{RT}$ in the NACT group compared to $80 \%$ in the radical surgery group $(\mathrm{p}<0.01) .{ }^{10}$ In a meta-analysis of individual patient data of patients treated with NACT followed by surgery compared with radical RT alone, data from 5 trials and 872 patients was obtained. The combined results from all trials $(\mathrm{HR}=0.65,95 \% \mathrm{CI}=0.53-0.80, \mathrm{p}=0.0004)$ indicated a highly significant reduction in the risk of death with NACT, but there were some differences between the trials in their design and results. ${ }^{13}$

In a meta-analysis, Kim et al reviewed data of five randomized trials and four observational studies. ${ }^{11}$ In patients with stage IB1-IIA, NACT prior to surgery reduced the need for adjuvant radiation therapy by decreasing tumor size and lymph node metastasis, and distant metastasis but it failed to improve survival compared to patients who underwent primary surgery. ${ }^{11}$ Rydzewska et al for the recently cochrane database of systematic reviews, have analyzed the results of six 
randomized studies. ${ }^{12}$ Both overall survival $(\mathrm{HR}=0.77$, 95\% CI 0.62-0.96, $\mathrm{p}<0.02$ ) and progression -free survival (PFS) were significantly improved with NACT (HR=0.75, 95\% CI=0.61-0.93, $\mathrm{p}=0.008)$. There was no difference in the effect of NACT with respect to total cisplatin dose, chemotherapy cycle length or cervical cancer stage. ${ }^{12}$

\section{CONCLUSION}

NACT administered at a shorter interval (e.g., weekly) prior to radical surgery for patients with early-stage cervical cancer (IB2, IIA) appears to be associated with an improved response rate and progression-free survival. However, the impact on overall survival remains to be confirmed. The present management of cervical cancer requires a multidisciplinary team approach. For patients with early disease, the plan to go for upfront surgery or NACT followed by surgery should be based on systematic review of clinical findings, pathology, imaging and availability of surgical skills which allows the patient to make informed decision about initial treatment modality.

\section{Funding: No funding sources \\ Conflict of interest: None declared \\ Ethical approval: Not required}

\section{REFERENCES}

1. Prakash G, Kumar L. Chemotherapy for cervical cancer: an update; in Rajaram S (ed): cancer cervix, edition $1^{\text {st }}$. New Delhi, Jaypee Brothers Medical Publishers Pvt. Ltd.; 2011:214.

2. Sharma A, Kumar L. Cancer of the cervix: what is better?. Natl Med J India. 2018;31:97-8.

3. Sananes C, Giaroli A, Soderini A, Guardado N, Snaidas L, Bermudez A, et al. Neoadjuvant chemotherapy followed by radical hysterectomy and postoperative adjuvant chemotherapy in the treatment of carcinoma of the cervix uteri: long-term follow-up of a pilot study. Eur J Gynaecol Oncol. 1998;19:368-73.

4. Hwang YY, Moon H, Cho SH, Kim KT, Moon YJ, Kim SR, et al. Ten-year survival of patients with locally advanced, stage ib-iib cervical cancer after neoadjuvant chemotherapy and radical hysterectomy. Gynecol Oncol. 2001;82:88-93.

5. Chang TC, Lai CH, Hong JH, Hsueh S, Huang KG, Chou $\mathrm{HH}$, et al. Randomized trial of neoadjuvant cisplatin, vincristine, bleomycin and radical hysterectomy versus radiation therapy for bulky IB and IIA cervical cancer. J Clin Oncol. 2000;18:17407.
6. Benedetti-Panici P, Greggi S, Colombo A, Amoroso M, Smaniotto D, Giannarelli D, et al. Neoadjuvant chemotherapy and radical surgery versus exclusive radiotherapy in locally advanced squamous cell cervical cancer: results from the Italian multicenter randomized trial. J Clin Oncol. 2002;20:179-88.

7. Napolitano U, Imperato F, Mossa B, Framarino ML, Marziani R, Marzetti L. The role of neoadjuvant chemotherapy for squamous cell cervical cancer ( $\mathrm{Ib}-$ IIIb): a longterm randomized trial. Eur J Gynaecol Oncol. 2003;24:51-9.

8. Eddy GL. Neoadjuvant chemotherapy before surgery in cervical cancer. J Natl Cancer Inst Monogr. 1996;(21):93-9.

9. Cai HB, Chen HZ, Yin HH. Randomized study of preoperative chemotherapy versus surgery for stage IB cervical cancer. J Obstet Gynecol Res. 2006;32:315-23.

10. Katsumata N, Yoshikawa H, Kobayashi H, Saito T, Kuzuya K, Nakanishi T, et al. Phase III randomized controlled trial of neoadjuvant chemotherapy plus radical surgery vs radical surgery alone for stages IB2, IIA2, and IIB cervical cancer: a Japan clinical oncology group trial (JCOG 0102). Brit J Cancer. 2013;108:1957-63.

11. Kim HS, Sardi JE, Katsumata N, Ryu HS, Nam JH, Chung HH, et al. Efficacy of neoadjuvant chemotherapy in patients with FIGO stage IB1 to IIA cervical cancer: an International collaborative metaanalysis. Eur J Surg Oncol. 2013;39:115-24.

12. Rydzewska L, Tierney J, Vale CL, Symonds PR. Neoadjuvant chemotherapy plus surgery versus surgery for cervical cancer. Cochrane Database Syst Rev. 2012;12:CD007406.

13. Neoadjuvant chemotherapy for locally advanced cervical cancer: a systematic review and metaanalysis of individual patient data from 21 randomised trials. Neoadjuvant chemotherapy for cervix cancer meta-analysis collaboration (NACCCMA Collaboration). Eur J Cancer. 2003;39:2470-86.

14. Neoadjuvant chemotherapy for cervical cancer metaanalysis (NACCCMA) collaboration: Neoadjuvant chemotherapy for locally advanced cervical cancer. Cochrane Database Syst Rev. 2004;2:CD001774.

15. Prakash G, Kumar L. Chemotherapy for cervical cancer: an update; in Rajaram S (ed): cancer cervix, ed 1. New Dehli, Jaypee Brothers Medical Publishers Pvt. Ltd.; 2011:215-221.

Cite this article as: Bharaswadkar G. Role of neoadjuvant chemotherapy followed by surgery in cervical cancer: a review. Int J Reprod Contracept Obstet Gynecol 2020;9:3912-4. 